

\title{
UNA EDUCACIÓN INICIAL COMPROMETIDA: HACIA LA PAZ Y EL DESARROLLO SOSTENIBLE
}

\author{
María Celina Chavarría González ${ }^{1}$
}

Recibido 12-1I-2003

Resumen: De cara a la sociedad del futuro es necesario que la educación inicial tome conciencia de incorporar al niño y la niña, a las madres, los padres y docentes en una educación problematizadora, que les permita tomar parte, colectivamente, de su vocación ontológica e histórica de humanizarse, vocación actualmente sujeta a la alienación disociativa, como nos recuerda la pedagogía crítica y el análisis de la modernidad. El viraje del Estado hacia el liberalismo económico y los papeles cambiantes de las mujeres en nuestras sociedades hacen que los sistemas de formación de la niñez se sitúen en una difícil encrucijada. Se constatan las carencias de reflexión profunda acerca de las posibilidades y significados del trabajo subvalorizado de las mujeres y de la educación inicial como instrumentos de transformación humana y social. Es con el fin de contribuir hacia ideales compartidos, desde un paradigma dialéctico, transaccional, humanista y feminista, que desglosamos una serie de principios que orienten nuestra mirada y nuestras acciones en este ámbito. Asimismo, nos mueve el requerimiento de esbozar una serie de ideales coherentes que sirvan como parámetros de calidad para la evaluación de programas de educación inicial. El presente artículo hilvana estos lineamientos generales.

Palabras clave: Pedagogía Crítica, Paradigma Transaccional, Teoría Sociohistórica, Currículo Oculto, Feminismo, Educación Inicial, Evaluación.

\begin{abstract}
"Tenemos el conocimiento de nuestro impacto sobre el ambiente, podemos percibir la contaminación y la degradación de la tierra, el agua, el aire -pero no le prestamos atención... Tal vez sería más exacto y justo decir que los individuos se sienten incapaces de responder al mundo natural apropiadamente, porque las instituciones políticas, económicas y educativas en las que estamos involucrados tienen una disociación construida en su seno. La alienación disociativa ha sido una característica distintiva de la cultura occidental por siglos...” Ralph Metzner (1995:65, traducción y destacado de la autora).
\end{abstract}

La conciencia de la vulnerabilidad de Gaia, bello Planeta Azul, representa quizás un signo esperanzador de nuestros tiempos. Sin embargo, las condiciones de alienación disociativa en las cuales se halla inmersa la formación cotidiana de la niñez tienden a manifestarse, invisibilizadas, en el currículo oculto. Es en la infancia temprana que se instaura la confianza básica, fundamento de una autenticidad interior ${ }^{2}$ frente a los embates sociales cambiantes que caracterizan la modernidad, por lo que la educación inicial se encuentra en un punto álgido ante la construcción del ser.

Con el fin de contribuir a una educación inicial para la paz, fundamentada en un concepto del yo pleno explícitamente contrapuesto al yo vacío y consumidor, este artículo esboza, en una primera parte, un escenario de la modernidad que se encuentra en el trasfondo de la construcción 
del ser y lo condiciona. En una segunda parte, articula un conjunto de principios coherentes con una visión epistemológica dialéctica, humanista y feminista, que orienten nuestra mirada y nuestro quehacer en el ámbito de la educación inicial. Al constituir un norte compartido, cumplen además la función de parámetros de calidad para la evaluación de programas de educación inicial.

Es la oportunidad de derivarlos hacia la comunicación intersubjetiva y entrelazarlos en lo cotidiano lo que apoya su posibilidad de trascender del campo teórico al campo de las vivencias que nos empoderan como actores sociales (cf. Habermas, 1987, 1989). Oportunidad que el Centro Infantil Laboratorio (CIL) ha acogido en sus prácticas, entretejiendo en su quehacer los principios que aquí se retoman, por lo que este artículo representa una autoría en equipo (cf. Chavarría et al., 2000a, 2000b).

\section{La educación de nuestros pequeños seres se gesta en el presente: retos del siglo XXI}

"La paz mundial somos nosotros...cada uno es un agente de la visión de paz que llevamos dentro." Kathleen Van de Kieft (1988:71).

Cada época histórica crea un sí mismo y una cosmovisión que mantenga las condiciones de su reproducción. A la vez, sus contradicciones generan la semilla de su transformación (cf. Cushman, 1990). La alienación disociativa inherente a la modernidad es tanto más importante cuanto los sistemas abstractos tienen un papel cada vez más omnipresente en los diversos ámbitos de la vida diaria y ejercen control sobre la creación de un sí-mismo vacío, alienado, que se encuentra, como actuante situado, relativamente impotente ante la trama de estos sistemas abstractos y lineamientos económicos que actualmente abogan por el individualismo, el consumismo, la indulgencia de los deseos (cf. Cushman, 1990; Freire, 1970; Fromm, 1965, 1969; Giddens, 1995; Habermas, 1987, 1989; Salas, 2000). "Es un hecho innegable que la modernidad despoja", nos precisa Giddens, y los procesos de despojamiento "... alcanzan no sólo el terreno de la vida cotidiana sino el corazón del yo" (1995: 244).

En aras de contribuir con la construcción de una educación inicial mediante la cual, uniendo nuestros esfuerzos, podamos favorecer una política de vida que desarrolle propuestas en torno a la pregunta "¿cómo hemos de vivir?"3, esbozamos una serie de retos que nos presenta la enajenación contemporánea del capitalismo tardío:

- $\quad$ Falta de espacio y tiempo para crecer en los goces y en la fuerza del amor. Premura para las labores de educación y formación, para las cuales se requiere holgura, pero cuyos beneficios sólo pueden apreciarse 20 ó 30 años más tarde.

- $\quad$ Soledad y recargo en que muchas mujeres han de formar a sus hijas e hijos.

- Pérdida del poder convocatorio y educativo de la familia.

- Desplazamiento de los valores de solidaridad, históricamente sustentados por las mujeres, ahora desalojados por el individualismo, el pragmatismo, el egocentrismo.

- Formación de un yo consumidor, hambriento. Valor propio en el tener, no en el ser.

- Grandes enclaves de pobreza y de miseria.

- Espacio urbano de gran inseguridad, conglomeración, contaminación, ruido, ausencia de espacio verde, peligros propios de nuestras ciudades. 
- Destrucción ecológica y contaminación.

- Debilitamiento de formas tradicionales de aprender mediante el contacto directo y la participación significativa en actividades productivas (cf. Lave y Wenger, 1991; Rogoff, 1990, 1994, 1997).

- Segregación horizontal en grupos de coetáneos de edades y clases sociales homogéneos; acceso muy restringido a las condiciones de existencia de otras clases sociales; carencia de contacto estrecho con seres más frágiles y con modelos inter-generacionales que nos muestren cómo ser hombres y mujeres adultos.

- $\quad$ Asignación a la infancia de gustos estereotipados y lugares específicos (escuelas, playgrounds, restaurantes de comida rápida, los cuales, con múltiples atractivos, se dirigen a seducir el consumo, capturando el interés de la niñez).

- Centralización de la educación y desintegración de su poder transformador hacia la construcción de una sociedad más humana: formación de pasividad temprana y baja autoestima; contribución a la impotencia y sentido de insignificancia personal; segmentación de la experiencia vital; carencia de una visión holística e interdependiente de la vida; falta de apreciación por otras culturas.

- La familia y la psique en manos de la televisión: actitud de espectador pasivo; programación televisiva de valores consumistas; fragmentación de la atención y del espacio de comunicación familiar; violencia como espectáculo, en frío, trivializada; valores de las jóvenes y los jóvenes en manos de programas muy atrayentes, realizados y desplegados por corporaciones cuyos intereses se contraponen al desarrollo armónico.

- Frivolización de la palabra. "De tanto usurpar significados, las palabras se quedan sin ninguno" (FernándezChristlieb, 1987).

- $\quad$ Crisis de legitimación y motivación política (Habermas, 1976).

- Creación de un desorden nombrado como nuevo orden mediante una nueva retórica; restricción paulatina de la conciencia.

En Costa Rica, los ideales de la Escuela Activa se habían venido enunciando en diferentes momentos del siglo XX, calando un lugar privilegiado en nuestras conciencias (Monge Alfaro y Rivas Ríos, 1978). Cabe recordar cómo las ideas preclaras y las prácticas de vanguardia de educadoras y educadores visionarios como Omar Dengo, María Isabel Carvajal o Luisa González se siembran en los corazones y los ideales de una generación de pedagogos costarricenses. Cobran especial importancia para hablar de paz y de desarrollo sostenible Aguijoneadas por los ideales de igualdad y justicia social y siguiendo los principios de la Escuela Activa, María Isabel Carvajal (Carmen Lyra) y Luisa González habían iniciado, en 1928, un preescolar montessoriano en un entorno de extrema pobreza urbana: el "kinder Montessori", en el edificio Metálico, que aún guarda ese nombre. Los recuerdos de Luisa González nos remiten a ese gran contexto carente y problemático ante el cual aquella inspirada experiencia, aún movida por bellos ideales, no podía ni ignorar ni hacer frente (González, 1990).

Sin embargo, al menos dos obstáculos tienden a impedir una práctica coherente con una educación viva y humanista (Chavarría, 1993): 
1. La falta de una consistente voluntad política que se proponga hacer real la posibilidad de una educación de esta naturaleza, inclusive en la educación inicial, historia que se repite en muchos países (véase, p. ej., Cordero, 2002; Chavarría, 1982, 1993; Meyer, 2000, 2001; Steinfels, 1973).

2. En nuestra formación como docentes, se perfila una dificultad fundamental para vislumbrar y explorar las posibles formas de llevar a la práctica nuestros ideales y principios, de modo que renunciamos a ellos para acomodarnos a una serie de menúes prácticos. "En tanto que la educación verdadera crea las fuerzas vivas de la acción, la instrucción aislada solamente sirve para aplicar y dirigir procedimientos consagrados. [La pedagogía pragmática, informativa] deja de lado la transformación del ser para exaltar y justificar lo que existe" (Merani, 1973:110).

En relación con la voluntad política, en 1992 y 1993, por ejemplo, habíamos dado a conocer un amplio análisis sociohistórico que reforzaba la necesidad de un compromiso más consciente del Estado en este campo (Chavarría y Pérez, 1992; Chavarría, 1993). Diez años después, sin embargo, se acentúa la tendencia neoliberal de dejar el crucial aspecto de la atención de la infancia más necesitada en manos de los limitados recursos y posibilidades de organización de las comunidades específicas, haciendo caso omiso de las condiciones que llevan a la ampliación del trabajo asalariado de la mujer. Paralelamente, las visiones ideológicas del Estado intentan escolarizar a edades cada vez más tempranas -con el consecuente estímulo a la economía, a la vez que creciente desempoderamiento- como nuestras investigaciones recientes atestan (Chavarría, Orozco, Chacón et al., 2000a, 2000b). Esta orientación estatal hacia una escolarización desarticulada contribuye aún más al fraccionamiento de la calidad de vida de las mujeres, al desempoderamiento y recargo en sus luchas, a una exacerbada opresión de género. Analizábamos:

"En el campo socioeconómico, la incorporación de la mujer a la fuerza laboral cumple una función tripartita:

a. amplía la oferta de trabajo en relación con la demanda, lo que faculta un descenso general en el nivel de salarios.

b. apoya una subsistencia familiar con salarios individuales inferiores a lo necesario. Esto, a su vez, permite ampliar la capacidad de consumo de las familias y sirve de "estímulo" a la economía.

c. apoya, además, el mejoramiento de las condiciones de vida y educación necesarias cuando aumenta la composición orgánica del capital, condiciones necesarias para la producción contemporánea, pero cuyos efectos, a largo plazo, no son medibles en función del mantenimiento inmediato de la fuerza de trabajo, por lo que su desarrollo social se ve limitado desde su inserción misma en la estructura social" (Chavarría, 1993: 107-109).

Como reflejo de esta triple función y las características de Costa Rica como país dependiente, se presenta una tendencia a subvalorar y fragmentar el trabajo de las mujeres dentro y fuera del hogar, incluyendo, por supuesto, nuestro papel como educadoras. Un fuerte viraje hacia el liberalismo económico resta importancia a las políticas estatales de protección y hace que los sistemas de formación de la niñez se sitúen ante una difícil encrucijada: por un lado, son necesarios para mantener las condiciones de producción dentro de los modelos de democracia política; por otro, representan un costo difícil de asumir, pues sus efectos son visibles sólo a mediano plazo. Insistíamos:

"De cara a la sociedad del futuro es necesario retomar el papel transformador de las mujeres y los niños en el establecimiento de relevantes valores de convivencia. $\mathrm{Al}$ sacar a la luz pública lo que ha sido relegado a lo doméstico. Lo que ha sido valorado, pero no reconocido, 
no nombrado: el trabajo social e invisible de las mujeres, lo que las mismas mujeres han aprendido a mantener en silencio y a escondidas mientras la sociedad de los hombres se organiza en torno a ellas. Organiza los valores, las guerras, lo económico. Organiza, incluso las formas que toman las guarderías" (Chavarría, 1993:107-108).

El presente artículo hilvana estos lineamientos generales. Se complementa, en lo práctico, con instrumentos diseñados con el fin de aquilatar nuestra orientación en centros educativos concretos, con la esperanza de ofrecer puentes coherentes entre nuestras teorías y nuestras prácticas, acordes a una visión de equidad de género y transformación social (Chavarría, 1991a; 1991b; Chavarría y Orozco, en proceso-a, en proceso-b):

a. La necesidad de que la educación preescolar tome conciencia de los papeles cambiantes de la mujer en nuestras sociedades, y de ese modo sirva realmente como instrumento de transformación humana y social.

b. La necesidad histórica de romper con estructuras predeterminadas de formación para activamente buscar soluciones creativas en este campo.

c. La necesidad de incorporar al niño y la niña y a sus madres-padres en una educación problematizadora, es decir, que les permita tomar parte, colectivamente, de su vocación ontológica e histórica de humanizarse (Chavarría, 1991a:13).

\section{Principios de una educación inicial tendiente a la construcción de un futuro de paz, equidad y armonía: la transformación del ser ante los retos del siglo XXI}

"Lo más importante como fuente de fortaleza es saber lo que quieres para tu alma. Porque lo que deseas para tu alma es lo que debes dar a los demás, incluyendo a tus hijos." (Bramadat, 1995).

El currículo se encuentra tanto en el entorno como en nuestra filosofía-en-acción (Apple, 1988; De Alba, 1993; Giroux, 1990). De hecho, siempre actuamos de acuerdo con nuestra interpretación de la realidad. ¿Cómo y para qué hacerla consciente? Sin embargo, cada uno de nuestros actos es una afirmación cultural y conlleva un concepto del ser humano y sus posibilidades.

Esbozamos a continuación una filosofía de la educación basada en una concepción psicológica, antropológica, filosófica, pedagógica, sociológica, epistemológica y ética del ser humano y de la sociedad 4 . Comúnmente conocidos como los fundamentos de un currículo, los presentamos en forma entrelazada, en torno a una sola educación para la vida.

\section{Paradigma de ser humano integrado}

"El amor se descubre a través de la práctica de amar y no de las palabras.” Pablo Coelho (1998:25).

Dos paradigmas del ser se encuentran actualmente en el foro de las concepciones de sociedad. Al representar nuestras ideas acerca de la naturaleza humana, tienen implicaciones prácticas sobre el quehacer educativo, por lo que es importante hacerlos conscientes (Giddens, 1995; Roszak, 1995). El modelo del individualismo autocontenido propone un ser separado, independiente, cuya orientación en la vida es casi exclusivamente el logro de su bienestar personal. Al adecuarse a las condiciones que la modernidad sustenta, esta concepción afianza la reproducción ampliada de esta formación socioeconómica. Es, por consecuencia, la que hoy tienden a privilegiar las instituciones sociales.

¿Qué consecuencias genera el paradigma del individuo autocontenido? Críticas dirigidas a la cultura occidental sugieren que esta sobrevaloración de lo individual ha conducido a la alienación, el aislamiento, la invisibilización y la desvalorización de las 'minorías', de los quehaceres asumidos por las mujeres y de los recursos de nuestro planeta. 
La continuidad y el desarrollo de la humanidad se encuentran actualmente amenazados por la extensión de la modernidad en esta nueva fase suya que es la globalización. Precisa, por tanto, propiciar una segunda concepción de persona: solidaria, comprometida, participativa y conciente de su pertenencia e integración a la naturaleza. Nos referimos al modelo alternativo de individualismo integrado, visibilizado por grupos no hegemónicos de la sociedad: las mujeres, las etnias minoritarias, los ecologistas y las ecologistas... En esta acepción salen a la luz y se tornan manifiestas las relaciones de interdependencia, en las cuales los problemas nos conciernen a todos y todas, a la colectividad. El sí mismo tiene un límite permeable, interconectado con los otros seres y procesos vivientes (Rozack, 1995). Esta visión nos insta no sólo a buscar la conexión entre las personas, y entre éstas y la naturaleza, sino también a transmitir este sentido de interconexión a los niños, las niñas y sus familias.

Como parte del movimiento creciente para trascender el paradigma de un sí mismo delimitado y aislado, Anita Barrows propone que se debe construir una nueva teoría del desarrollo infantil:

"Esta teoría debe tomar en consideración que el bebé nace no sólo en un contexto social sino también ecológico. Debe reconocer que desde los momentos más tempranos de la vida, el bebé tiene conciencia no sólo del contacto humano sino también del contacto de la brisa en su piel, de variaciones de luz y color, temperatura, textura, sonido [...] Curiosamente, esto no ha sido incorporado en nuestras teorías del desarrollo humano, para las cuales la única figura clave ha sido la madre" (Barrows, 1995:109).

\section{Paradigma transaccional o dialéctico: visión problematizadora y transformadora de la educación desde una filosofía humanista}

"La responsabilidad del [ser humano], cuya forma de conciencia trata de facilitar el análisis de la Existencia, es una responsabilidad encuadrada dentro del carácter peculiar y singular de su existencia, como algo único y que sólo se vive una vez; el existir humanamente consiste en ser responsable en vista de la finitud." Víctor Frankl (1946/1963:95).

Hemos considerado que los movimientos de las filosofías humanistas (el personalismo, el existencialismo dialéctico, la psicología sociohistórica y, en particular, la pedagogía crítica, conscientemente intentan dirigir las tendencias educativas en pos del rescate de las condiciones a la medida del ser humano y de una sociedad más justa ${ }^{5}$.

La pedagogía crítica, con sus orígenes en Paulo Freire, intenta reivindicar el carácter creativo del ser humano, como deconstructor y reconstructor de la realidad, una de las tareas más importantes en nuestra existencia (Giroux, 1988; 1990; Apple, 1989). Rescata el lugar de los educadores y educadoras como agentes de transformación, lo cual rebasa la función técnica asignada de implementar un currículo prediseñado.

La recientemente denominada cosmovisión transaccional, que comprende la perspectiva dialéctica, el enfoque existencial-fenomenológico y la teoría socio-histórica de Vygotsky, aporta la visión de que las personas, los procesos y los contextos no pueden ser definidos o comprendidos por separado, sino solamente tal como funcionan mutuamente, como aspectos de una situación, como relaciones cambiantes entre actores y contextos, no como procesos psicológicos por un lado y teorías y eventos del contexto social por otro (Altman y Rogoff, 1987/1991; Werner y Altman, 1998) ${ }^{6}$.

Esta perspectiva nos impide definir y etiquetar a nuestros jóvenes en términos particulares, instándonos más bien a comprender el flujo y la dinámica de los eventos que construimos, las acciones entrelazadas entre las personas y entre éstas y el ambiente, lo cual representa una práctica contestataria cifrada en la auto-observación y la reflexión con el fin de evitar esta práctica común. 
Los educadores y educadoras podemos ser agentes de cambio, transformación y avance, o portadores de estancamiento y esclerosis social, lo asumamos conscientemente o no. "La posibilidad a la que puede recurrir el individuo para apoderarse y ampliar su albedrío depende de su capacidad reflexiva para someter a debate los modelos propuestos e impuestos, o los bosquejos prefigurados de la interacción social" (Brenes, Lemineur y Sanabria, 1995:14). Una cosmovisión transaccional, dialéctica, requiere examinar, en forma sistemática y crítica, el contexto que propiciamos, nuestras propias actuaciones, elementos inextricables en la comprensión del desarrollo (cf. Chavarría, et al., 2000a, 2000b).

\section{Actividad espontánea, autoactividad en la gestión del sí mismo: hacia una cultura constructiva, de armonía y paz}

“...la verdadera libertad está indisolublemente ligada al conocimiento profundo de uno mismo y del proyecto propio". Susana Tamaro (1998:134).

Como expresión de sus individualidades, gestores de su quehacer intelectual, de sus acciones y de su estilo, los pequeños y las pequeñas deben tener la opción de tomar decisiones y de hacer por sí mismos aquello de lo cual son capaces, dentro de las limitaciones que dispone nuestra existencia. Les motiva un deseo muy fuerte por desarrollarse plenamente. Las valiosas oportunidades programadas para observar, explorar y experimentar posibilidades y limitaciones, autorregularse, aprender de estas experiencias, representan aquello que denominamos autonomía contextuada. Libertad relativa, pues como docentes solicitamos y modelamos actuaciones tendientes a la convivencia armoniosa y a la cortesía, ponemos límites de acuerdo con las necesidades del cuidado del ambiente y del bienestar de los demás. ¿Cómo nos conoceríamos si no podemos actuar espontáneamente y darnos cuenta de las consecuencias de nuestros actos? ¿Cómo conocer el mundo sin explorarlo?

La tendencia a trasladar actividades y formas de organización de la escuela a los centros de educación inicial desaprovecha las oportunidades de exploración que surgen con gran fuerza en estas edades. Ampliemos, más bien, las opciones mediante un ambiente y relaciones humanas en los cuales las jóvenes y los jóvenes puedan asumir responsabilidades con lo que se encuentra a su alcance y constituye su mundo, que se entrelaza como un tejido con el de otros niños y niñas, de otros adultos, de otros seres vivos con quienes compartimos este planeta, en interdependencia y unión indisoluble.

Asimismo, la paz en el cuerpo se sustenta en la posibilidad de actuar y sentir de acuerdo con uno mismo y en el reconocimiento de los sentimientos. El sí mismo es el "instrumento" más valioso que tenemos para conocer y actuar en la realidad. ¡Un yo pleno inicial que nos permita luchar contra el yo vacío (y consumidor) propiciado por nuestra cultura modernizante!

Cuando se conforma al niño y la niña a una norma que no corresponde a sus características ni a los imperativos de su edad evolutiva, la experiencia puede ser dañina. Cuando se les pide que se desatiendan a sí mismos para atender los mandatos y deseos generados por adultos, se corre el riesgo de que aprendan a no confiar, ni en éstos ni en sí mismos. Se corre el riesgo de que se conviertan en seres pasivos, subordinados a la autoridad. Alternativamente, podrán aprender formas de rebelión o de escape.

En la niñez, las personas somos maleables. Si se nos manipula, se nos atarán los hilos invisibles para que de adultos, respondamos de una manera cuando se tira de uno de los hilos, de otra cuando se tira del otro y, desorganizadamente cuando los hilos son contradictorios... Esta práctica nos 
deja vulnerables a la manipulación actitudinal, política e ideológica, útil sólo para quienes es conveniente tal estado de cosas.

"Esta "hipernormalidad" se va apoderando poco a poco de nosotras hasta hacer que nuestra vida se convierta en algo rutinario, en una existencia exánime sin que nosotras lo queramos realmente. Esto fomenta que no se preste atención a los dictados de la intuición, lo que a su vez conlleva una falta de iluminación psíquica” (Estés, 1992/1995: 149).

Esto debe rebasar el marco de las palabras y los ideales para convertirse en una práctica cotidiana. Como señalaba Doke (1975), en un buen preescolar, los chicos y chicas tendrían el poder de decisión sobre sus propias actividades durante más del $80 \%$ del tiempo. Esta práctica, por supuesto, sólo puede realizarse si buscamos las condiciones de apoyo, tanto en el ambiente preparado como en la colaboración de otras personas.

\section{El amor, la interdependencia y el respeto como principios en el trabajo con estos pequeños seres}

"Como sucedía antiguamente, la tarea principal de la madre Lakota era enseñar al nuevo niño que él o ella estaba conectado con todo en el círculo de la vida. Llevaba al niño a caminar y decía: ‘¿Ves la ardilla? Es tu hermana. ¿Ves el árbol? Estamos relacionados. Esta es tu familia, todo esto es tu familia'. Al ser criados de esta manera, sabían profundamente que todos estaban entrelazados unos con otros, que todos eran una familia, todos eran conscientes. Los niños Lakota tenían la oportunidad de comenzar pronto en la vida a atender a la totalidad o lo sagrado, a la dimensión espiritual de las cosas, y luego extender esta capacidad poderosamente a medida que crecían." Brooke Medicine (1997:77-78).

El modelo individualista, soporte de nuestra sociedad modernizante, presenta una distorsión teórica al proyectar un ideal de independencia y autonomía. En realidad, nos construimos siempre en sociedad, interdependientemente.

¡Sería pertinente que las ciencias sociales y la educación contribuyan hacia la consolidación del paradigma conducente a la ampliación de opciones por la colectividad y el desarrollo sostenible! Mostrar a los chicos y las chicas formas de respetar y amar la vida propia y la de sus semejantes representa un aporte hacia el modelo de ser humano integrado. Esto supone, primero, fomentar el respeto por sus propios espacios y expresiones, en tanto no lesionen a otros, en formas prácticas y que trasciendan las exhortaciones verbales.

"Las graves pérdidas de poder que nos llevan a dudar de nuestro valor como seres dignos de atención, respeto y solicitudes por parte de los demás dan lugar a una dolorosa y enfurecida decisión infantil de no permitir en la edad adulta que nos vuelvan a lastimar de la misma manera" (Estés, 1992/1995: 572).

Esto implica trabajar por las condiciones necesarias. Para establecer este vínculo, tan significativo para los pequeños y las pequeñas como para las adultas, es necesario propiciar condiciones en que haya continuidad en los grupos y docentes, año tras año, en los casos de permanencia de los infantes en un centro infantil por más de un año ${ }^{7}$. Pedirle a un pequeño o una pequeña, apenas aventurándose en el mundo, que pase gran parte de su vida entre 30 o más personas coordinadas por una adulta, es pedirle demasiado. Representa, además, una carga demasiado onerosa para la adulta. Para centros de jornada completa, Hymes (1974) sugiere grupos de 12 niños por dos adultos para menores de tres años o menos; 16 por dos adultos para los de cuatro; 20 por dos adultos para los de cinco $^{8}$. Sugiere que aún cuando sea necesario ampliar el número de niños por grupo, debe mantenerse la norma de dos adultos o adultas presentes para mantener la escogencia libre y la atención personal.

Habría maneras creativas de enfrentar estos asuntos ${ }^{9}$. Conviene reflexionar profundamente si al bajar la edad de ingreso a la educación inicial, para jornadas de tiempo parcial, careciendo de las condiciones necesarias, estamos contribuyendo 
con el cansancio que puede experimentar nuestra niñez a lo largo de una prolongada exposición al sistema educativo. Asimismo, con la consolidación de una sumisión o pasividad tempranas, más que con su formación.

\section{La vida es una: una educación para la vida, no una vida para la educación}

El desarrollo no es un proceso fundamentalmente biológico, sino culturalmente organizado. Según Vygotsky, el proceso de apropiación de la cultura

"se realiza durante la actividad que el niño desarrolla con respecto a objetos y fenómenos del mundo, del entorno, en los que se concretan esas adquisiciones de la humanidad. Dicha actividad no puede formarse por sí misma en el niño, se forma mediante la comunicación práctica y verbal con las personas que le rodean, en una actividad común con ellos" (Leontiev, 1983:262).

Es imprescindible un entorno de utilidad y significado social que promueva un enlace entre la intencionalidad y enriquecedoras actividades productivas, constructivas tanto para la formación de las jóvenes y los jóvenes como de la vida social (mundo de vida). Como insiste Bruner (1967), trabajar por metas externas, en el contexto de ejercicios pedagógicos carentes de significado vital y comunal, ¿es una forma de domesticar nuestra voluntad, para que luego, de adultos, nos conformemos con las indicaciones de otros sobre cómo deben transcurrir nuestras vidas?

En la actualidad, amplias facetas de lo cotidiano han sido sustraídas del concepto de sí y colocadas en manos de especialistas. La alimentación, la salud, la moral, la educación, el curriculum, la comunicación, la recreación, el tiempo libre, la pasión han sido delegados a sistemas autónomos que se especializan en estos ámbitos, con un consecuente vaciamiento del ser, al cual Giddens
(1991/1997) se refiere ampliamente como un proceso de secuestrar la experiencia.

Es primordial darnos cuenta de que los centros infantiles dirigidos al "preescolar" no son pre-escuelas, son centros formativos de la niñez, de primerísima relevancia para el desarrollo total de la personalidad. No son escuelas preparatorias para primer grado, cuyos objetivos con frecuencia se dirigen a un "aprestamiento" dirigido al entrenamiento en pequeñas habilidades específicas que supuestamente preparan para la escolaridad, pero poco significativas en términos de los momentos formativos y períodos sensibles. Denotan además una falta de creatividad, un pensamiento lineal objetivos-métodos, por parte de una tecnología educativa que pasa por alto y desvaloriza las fuerzas culturales propias, la formación de destrezas y la consolidación de la personalidad ya logradas en el entramado de la vida cotidiana (Hernández, 2000). Asimismo, la socialización de conductas y actitudes escolares aceptadas: obediencia, atención-a-lo-quela-maestra-dice, conformismo, "participación", orden... no son metas ni suficientes ni deseables desde una perspectiva totalizadora $^{10}$.

¿Participamos de este vaciamiento del ser al dejar de asumir consciente y cabalmente, en lo cotidiano, las posibilidades que como seres humanos y como docentes de preescolar podemos abrir? Por ejemplo, separar los desechos para elaborar abono orgánico, que luego ellos y ellas mismos preparan, empacan y venden con gran ilusión, ha sido una enriquecedora experiencia que Mabel Ovares y Marcela Hio, desde el CIL, han introducido en los grupos de cuatro y cinco años. Contribuir con la abonera, hacer tortillas, pelar, rallar y cortar los alimentos, cultivar la huerta, servirse una taza de té, una galleta o un fresco, enriquecen la conciencia... Al compartir experiencias cotidianas con los niños y niñas, les transmitimos su importancia. Aprenderán que la vida está llena de pequeños actos, sentimientos y 
acciones que implican deberes y derechos para quienes las llevan a cabo. Aprenderán a sentir y expresar amor, solidaridad, respeto, a amarse y a amar a otros y otras.

Como docentes, al reencontrar nuestras raíces en la infancia, valorándolas, podemos encontrarnos con los pequeños y las pequeñas desde una fresca apreciación de la cultura y de la niñez. Contribuimos a humanizar nuestro rol profesional; por ende, a un paradigma menos cercano a lo administrativo y más cercano a la vida.

\section{Igualdad de oportunidades y consciencia de género}

"Cosmovisiones que valoren una obra de arte o una nueva tecnología tanto como un árbol o un río; la pasión tanto como la lógica, la conducta heroica tanto como los actos cotidianos de sobrevivencia. Cosmovisiones que broten de lo erótico tanto como del corazón o del intelecto. Tengo la esperanza de que a través de esta re-evaluación empecemos a comprender que macho y hembra, cultura y naturaleza, pensamiento y sentimiento no son dicotómicos sino elementos de una ecuación: la ecuación de la vida.” Alda Facio (1997: 47).

Al nacer, el niño y la niña despiertan a la vida, al contacto con nuevas e impresionantes experiencias. Pero si desde la infancia segmentamos la experiencia en diversiones de hombres y quehaceres de mujeres, distorsionamos y limitamos sus posibilidades de ser, de actuar, de sentirse y de conocerse.

Un ambiente que abre las oportunidades para que tanto las niñas como los niños participen de lleno en el acune de las muñecas, el lavado de platos, la limpieza de mesas, los juegos de legos y de carpintería, representa una lucha contra los estereotipos de género. Ayudamos a revertir patrones culturales al limitar, para hombres y mujeres, ciertos días en el uso de materiales encasillados según el género (de construcción, del cuidado de bebés, de artes... $)^{11}$. Lo femenino es sistemáticamente visibilizado y resaltado al referirnos a "los niños y las niñas", "las personas".

\section{La conformación de un estilo de vida conducente a la paz y al desarrollo sostenible: experiencias entrelazadas en el cuerpo}

Al colonizar el presente, al implantar un estilo homogéneo de hacer las cosas (de vestir, de comprar, de recrearse), al poner su sello en lo cotidiano y convertirlo en lo nocuestionado, la modernidad coloniza asimismo el futuro, pues dificulta vislumbrar un futuro distinto (Giddens, 1995). Paso determinante en la educación inicial, donde se asimila (se in-corpora) un estilo de vida, lo mismo que la suficiente seguridad y satisfacción personal como para luego optar, reflexivamente, por estilos y políticas de vida alternativos, asumidos conscientemente.

Nuestro entorno y la conducción del quehacer en un centro infantil, ¿propician un estilo de paz? Nuestros pequeños y pequeñas, ¿cómo han de experimentar armonía, si no les damos oportunidades de involucrarse en actividades tendientes a su auto-construcción, a su propio ritmo? ¿Si les sometemos a ambientes tensos, duros, bulliciosos y, aún cuando están concentrados en actividades formativas, les interrumpimos constantemente con las rutinas?

Cuando las niñas o niños no pueden decir a la docente "no quiero participar en esta actividad", es frecuente que expresen su enojo pateando o desordenando al grupo. Es importante validar sus sentimientos y ofrecer opciones reales ¡No podemos construir la paz a partir de coartar las posibilidades de expresarse, a partir de la imposibilidad de defender su espacio, a partir de la frustración "de a callado"! ¿Cómo podemos contribuir a un ambiente de paz si se nos cercena la posibilidad de expresar nuestro enojo, incomodidad y voluntad, en formas que no lesionen a otras y otros?

La mediación de los altercados es de relevancia singular, al mostrar y modelar formas de negociación y resolución 
de conflictos. No podemos construir la paz tratando de hacer calzar a nuestros pequeños y pequeñas con un estereotipo de lo que significa portarse bien. El enojo tiene razón de ser, debe tener un lugar en la construcción de la paz. Asimismo, la expresión de nuestra voluntad, de nuestro desacuerdo, debe ser canalizada y modelada.

Nuestra sensibilidad particular nos hace vulnerables al condicionamiento, a la sutil desinformación ideologizada, a los ambientes de armonía o tensión. Al querer agradar, ser aceptados, amados, admirados, somos vulnerables a condiciones que nos sacan de nuestro centro, lo cual nos deja una sensación de frustración, de pobreza de significados, de irritabilidad, de desasosiego.

¿Cuántas solicitudes de conformidad y obediencia hacemos a nuestros pequeños y pequeñas en el lapso de una mañana? ¡Una educación para la paz requiere de personas que se respeten a sí mismas, que logren vivenciar un sentido de tranquilidad en el cuerpo, de armonía con los otros y consigo mismos! Saber que pueden tomar agua, probar un té de hierbas, ir a la biblioteca o escoger las actividades de su agrado a su propio ritmo es muy satisfactorio.

Sobre las significativas vivencias de paz en el cuerpo resaltamos que es la relación con el propio cuerpo la que permite el permanente descubrimiento de los atributos y recursos personales; asimismo, las posibilidades de interacción con el entorno y con las demás y los demás (Giddens, 1995). ¡Imprescindibles para asumir un futuro de paz y armonía!

Las actuales corrientes de ecopsicología parten del supuesto de que en los niveles más profundos, la psique permanece empáticamente vinculada a la Tierra que nos acunó. La adaptación del ser profundo al inconsciente colectivo es también la adaptación al mundo natural, orgánico e inorgánico. El ser más profundo, colectivo e inconsciente, es el mundo de la naturaleza (Roszack, 1995). Una relación estrecha con la naturaleza, estableciendo vínculos con su asombrosa multiplicidad y belleza, es extraordinariamente reconfortante para la psique. ¿Qué esfuerzos realizamos para propiciar experiencias de acercamiento y vínculo con la naturaleza, de confianza e intercambio estrecho con ella?

\section{La celebración de las diferencias y de la creatividad}

"Igualmente significativo es el hecho de que las escuelas son marcos evaluativos, y el estudiante no aprende sólo a ser evaluado, sino también a evaluarse a sí mismo y a los demás" (Giroux,1990: 75).

Celebrar y honrar a cada niña y niño como únicos es primordial para la conformación de personalidades seguras, dispuestas a contribuir en la sinfonía de la vida desde sus dones y visiones particulares. Estamos afirmando su derecho de ser y existir en este mundo, sin tener que amoldarse a nuestras expectativas. Esto significa evitar la comparación y el etiquetamiento.

Al servirles como modelos, al propiciar un espacio para el respeto mutuo, los chicos y las chicas también aprenderán a conocerse y honrar estas diferencias, lo mismo que a valorar y a respetar los materiales del ambiente, como derecho de los otros y las otras.

$\mathrm{Al}$ poner a su disposición una multiplicidad de elementos de apoyo, fomentamos la creatividad, la iniciativa y la seguridad personal. La existencia de diversos patrones de sensibilidad y de procesar la información ha sido bien documentada en una enorme cantidad de investigaciones sobre temas de introversión-extroversión, personalidad impulsiva-reflexiva, inteligencias múltiples, estilos de aprendizaje, entre otras. Su falta de reconocimiento implica una marginación de muchos niños y niñas del sistema escolar: aquellos cuyo estilo se contrapone a las normativas escolares. Nuestra educación parece especializarse en la formación de papeles más que en preparar las condiciones para asumir 
responsabilidades por nosotras y nosotros mismos (Chavarría y Pérez, 1992). ¡Esta marginación dolorosa de tantas personas no contribuye a la armonía social! En última instancia, conlleva también a la construcción de personalidades defensivas o enajenadas. Para luchar por la paz externa, son necesarias las vivencias de paz interior.

Como docentes, debemos también aprender a respetar nuestra propia personalidad y actuar de acuerdo con nosotras y nosotros mismos, con nuestras propias características, fortalezas y visiones, acceder al rescate de nuestra paz interior.

\section{Respetar los momentos de desarrollo}

"[Montessori] les dio a los niños un ambiente apropiado y libertad guiadas para que pudiesen actuar de acuerdo con sus necesidades, ritmo y compás interiores, y como resultado, revelaron características que antes no se les atribuían. Estas incluyeron una profunda y prolongada concentración, la repetición de ejercicios por cuenta propia, la necesidad interna por realizar un esfuerzo máximo, control de movimientos, un sentido de orden, y otros fenómenos." Mario Montessori, Jr. Educación para el desarrollo humano. (1986:32).

En las distintas etapas del desarrollo y en circunstancias históricas particulares, el aprendizaje sigue principios y leyes diferentes. ¡Con cuánta frecuencia actuamos como si unas cuantas 'etapas universales del desarrollo' pudiesen explicar y apoyar la planificación del aprendizaje, para todas las edades y contextos!, insistía Vygotsky, luego Wallon (1949) y Stern (1985).

En los diferentes ciclos de desarrollo, las pequeñas y los pequeños están absortos por dominar procesos idiosincráticos: "el niño es [entonces] sensible a ciertos aspectos del ambiente y está predispuesto a buscar experiencias que ejerciten las capacidades relacionadas con estas sensibilidades transitorias", expresa Meadows (1996: $2)^{12}$. ¡Aprovecharlas dará sus frutos!
Muchos ejercicios de la vida práctica diseñados por Montessori representaban apoyos a la actividad productiva de los más pequeños, un andamiaje ante su intenso deseo por lograr un mayor dominio hacia su participación plena en la cotidianeidad. Por ejemplo, el trasvase de granos con un cucharón sopero brindaba un puente para los pequeños y las pequeñas que todavía no podían servir la sopa. Al desestimar estos períodos sensibles, se pierde la oportunidad de un aprendizaje relevante, además de desmotivarles hacia otros aprendizajes posibles.

En una cultura letrada, entre los cuatro y los seis años se gesta un período sensible por interesarnos por "lo que dice ahí", por desear plasmar garabatos que tengan sentido, por fijarse en los sonidos componentes de las palabras, por atender a las grafías. Mucho antes de ingresar al primer grado y encontrarse con las estereotípicas sílabas ma - me - mi - mo - mu, están ávidos por escribir pequeños mensajes amorosos para sus madres, padres o abuelas y abuelos; felicitaciones de cumpleaños; rótulos de "PROVIDO ENTAR"... Desafortunadamente, a los siete años, esta sensibilidad especial ha perdido fuerza. Esperarse hasta la primaria antes de iniciar la escritura puede ser tan contraproducente como obligarles a hacer repetitivos ejercicios de aprestamiento carentes de sentido o interés para ellas y ellos.

Aprovechar el fermento especial de cada edad y abordar la enorme diversidad de períodos sensibles en un grupo de preescolares eran preocupaciones que Maria Montessori enfrentó, proponiendo la autoescogencia en un ambiente preparado, inicialmente como un acto de fe en el impulso hacia el crecimiento. A partir de una amplia gama de posibilidades diseñadas en torno a los puntos de interés para los niños y las niñas, cada quien optaría por materiales y actividades de acuerdo con sus inquietudes de desarrollo, siguiendo un deseo positivo de crecer y desarrollarse ('ser 
grande'). Esta es la pauta que siguen los modelos de marco abierto.

\section{La actividad significativa: más allá del juego}

"Condición del aprendizaje: sentir, apasionarse, entusiasmarse, amar.” Francisco Gutiérrez (1993:35).

Ante las tendencias ya señaladas de pérdida de contacto con las actividades del trabajo, con el amor, con los vínculos comunitarios, consideramos que la noción de actividad significativa planteada por Vygotsky nos brinda mayor poder analítico y mayor claridad que la de juego (Wertsch, 1981). Encierra más fuerza práctica que los conceptos de estimulación, trabajo o juego... ¿Pues qué es el juego o el trabajo para los pequeños sino actividad significativa? En efecto, los niños y niñas no sólo juegan; su actividad, muchas veces realizada con empeño y persistencia, más se asemeja a un trabajo de autoconstrucción, como bien había observado Montessori.

\section{El respeto por el ritmo de los procesos: paz en el cuerpo, paz con la naturaleza}

"Cada vez que te sientas extraviada, confusa, piensa en los árboles, recuerda su manera de crecer. Recuerda que un árbol de gran copa y pocas raíces es derribado por la primera ráfaga de viento, en tanto que un árbol con muchas raíces y poca copa, a duras penas deja circular su savia. Raíces y copa han de tener la misma medida, haz de estar en todas las cosas y sobre ellas: sólo así podrás ofrecer sombra y reparo, sólo así al llegar la estación apropiada podrás cubrirte de flores y de frutos. Y luego, cuando ante ti se abran muchos caminos y no sepas cuál recorrer, no te metas en uno cualquiera al azar: siéntate y aguarda. Respira con la confiada profundidad con que respiraste el día que viniste al mundo, sin permitir que nada te distraiga: aguarda y aguarda más aún. Quédate quieta, en silencio, y escucha a tu corazón. Y cuando te hable, levántate y ve donde él te lleve." Susana Tamaro (1998:186-187).

Nuestra civilización moderna requiere que nos movamos a un ritmo mucho más acelerado que el que gustosamente anhelan nuestras mentes, nuestro corazón, nuestros hijos e hijas, nuestra digestión, nuestra sexualidad, nuestra poesía, nuestro disfrute. El jardín de niños no es la excepción. Es desafortunado que así sea, pues en el campo educativo, un proceso encierra más lecciones estructurantes que un producto. ¡Cuánto más importante resulta el proceso de recortar y pegar concentradamente que aquello que se recorta, de lo cual nadie se acordará!

Somos un proceso, una danza. Es el movimiento, el proceso, el ritmo, lo que nos estructura. Estas vivencias del tiempo y del ritmo propio son determinantes para la construcción de una experiencia de paz en el cuerpo; un ambiente que propicie amplios espacios para la actividad espontánea representa un fundamento necesario.

\section{El movimiento como fundamento de un aprendizaje armonioso}

"Mirad a un niño cuando juega; miradlo cuando estudia. Comparad estas dos situaciones y alcanzaréis un fecundo conocimiento. ¿Sabéis de algún niño que el deseo de jugar haya impacientado durante el juego? El caso inverso sí lo conocéis: el del niño que se propone terminar pronto la tarea para entrar al coro en que los otros cantan. [...] Ahí la más fuerte sugestión: el estudio, vehículo de la luz, convertido en tortura [...] El motivo de meditación sería éste: el estudio debe realizarse en idénticas condiciones de espontaneidad que el juego.” Omar Dengo. (1915/1961:351).

En la niñez, no puede haber aprendizaje significativo sin movimiento. No podemos operar sobre la premisa de que para aprender, los niños y las niñas deben estar sentados. Coartar su movimiento significa sacrificar su iniciativa y su posibilidad de aprender algo útil o interesante para ellos, con el fin de que aprendan a ser obedientes.

"[...] los seres humanos, y en particular los niños, han sido obligados a llevar una vida inactiva, a realizar trabajo mental [...] artificialmente separado de los órganos que deberían permanecer conectados, y éstos incluyen no sólo el cerebro sino también los músculos y los órganos sensoriales. [...] En el área de educación, 
esto nos ha llevado a demandar una vida activa, es decir, un aumento en la actividad física, con la esperanza primaria de revivir e intensificar la vida vegetativa, la cual, cuando no está funcionando adecuadamente, se encuentra marcada por una falta de energía y una debilidad física, un descenso en el metabolismo [...] El adulto tratará de obligar al niño a que controle estos movimientos, con la inútil y monótona repetición de "estáte quieto". Por cierto, en estos movimientos el pequeñín está buscando el verdadero ejercicio que le organizará y coordinará los movimientos que son útiles al [ser humano]. Por consiguiente, debemos, desistir de tratar inútilmente de reducir al niño a un estado de inmovilidad (Montessori, 1914/1965; cit. por Meadows, 1996:1).

No se trata de un movimiento mecánico ni sensorial, sino intencional: "el punto de inicio de la movilidad no es motriz sino mental. El movimiento tiene gran importancia en el desarrollo mental mismo en la medida en que la acción esté conectada con la actividad mental en proceso" (Montessori, 1949/1967:71). Al propiciar que su actividad se encause hacia actividades constructivas, éstos se organizarán, instaurándose un sentido de activa tranquilidad. Es importante, por ende, no sólo proveer acceso a la movilidad intencional durante las actividades "formales" de aprendizaje, sino también a espacios que permitan una actividad más vigorosa.

\section{Valoración de la cultura y la naturaleza: el currículo culturalmente pertinente}

Tanto el contenido como el proceso de aprendizaje son importantes. No basta con "estímulos". Los materiales deben estar diseñados y organizados para brindar experiencias de calidad. Por ejemplo, las herramientas de carpintería, jardinería o cocina deben ser utilizables como tales, y así sucesivamente.

Una amplia oportunidad de inmersión en la naturaleza, al igual que para apreciar sus fenómenos y su relación con el ser humano, imprimen un sentir muy especial. Materiales tendientes al conocimiento y respeto por la naturaleza y las diversas culturas sustentarán una amplitud de miras especialmente relevante en el momento histórico actual. Es de singular relieve brindar una perspectiva de otras culturas y sectores sociales: esta maravillosa oportunidad de una naciente "visión cósmica" nos incita a tener un profundo respeto por la diversidad.

Las actividades cotidianas, culturalmente significativas son, dentro de un paradigma transaccional, esenciales para el desarrollo de un sentido armonioso y enriquecido del sí mismo. Es importante resaltar que aparte de los materiales que uno esperaría encontrar en un kínder tradicional, hay una serie de materiales muy significativos para el desarrollo armonioso en estas edades. Ahí donde la actividad comunitaria es más cercana, las niñas y los niños participan en las actividades que se llevan a cabo en su entorno: están tranquilos y ocupados, satisfechos, contentos. Cuando la madre lee o lava, los pequeños juegan a leer o ayudan a lavar; cuando el padre cocina o corta el zacate, las chiquilinas le rodean para ayudar. Imitan estas actividades y participan por gusto. Ahora acostumbramos a separarles desde muy temprano de la posibilidad de compartir con nosotros y nosotras. Los escolarizamos muy pronto, los mandamos a ver televisión, desconectándolos de su propia fuerza vital y conexión con la comunidad de humanos, con su participación amplia en la cultura. Les robamos su sentido de utilidad, solidaridad, pertenencia, contribución. Las chicas y los chicos necesitan desarrollar una participación plena en actividades que signifiquen un reto. Éstas se plasman como oportunidades de participar, de una u otra manera, del quehacer cotidiano.

$\mathrm{Al}$ igual que los legados culturales más amplios (libros, música, obras de arte, costumbres en otras culturas claramente destacadas) merecen resaltarse, en la coyuntura actual de globalización es de 
especial relieve rescatar valores culturales locales, recursos regionales, lingüísticos, musicales y humanos de nuestras comunidades. Para consolidar el sentido de pertenencia y amor personal en los niños y niñas, hacemos hincapié en el aprovechamiento de todo tipo de recurso que, siendo propio de nuestra cultura, estimule el conocimiento y la apreciación de diferentes manifestaciones culturales del país o región, integrados al ambiente cotidiano, no sólo como objetos de lecciones específicas (Peralta, 1996).

\section{Nuestro papel como profesionales e intérpretes culturales}

“... el educador ya no es sólo el que educa sino aquel que, en tanto educa, es educado a través del diálogo con el educando, quien, al ser educado, también educa. Así, ambos se transforman en sujetos del proceso en que crecen juntos y en el cual 'los argumentos de la autoridad' ya no rigen. Proceso en el que ser funcionalmente autoridad requiere el estar siendo con las libertades y no contra ellas (Freire, 1990, el énfasis es nuestro)."

Freire introduce el concepto de decodificación de lo cotidiano. Decodificar lo cotidiano implica mirar y analizar con ojo crítico y mirada fresca lo que se da en la variedad de quehaceres de un centro infantil, desde el recibimiento de los niños y niñas hasta su despedida, pasando por las rutinas de lavado de manos, comidas, siesta, recreo, hasta las actividades explícitamente planeadas para su formación. Significa también analizar nuestras teorías, lo mismo que la coyuntura actual.

En las etapas preescolares, el diálogo, esencia de la educación para la libertad, se mantiene y posibilita a través de la perspectiva de los adultos y adultas como investigadores de la experiencia de los chicos y chicas, quienes frecuentemente expresan sus opiniones y su sentir en formas muy incompletas. Las palabras de los niños y niñas muchas veces son sus gestos, sus acercamientos, sus agresiones, su actividad y concentración, su inquietud, sus intereses, su conducta exploratoria. Esto nos reta a observarles para intentar comprender sus acciones a la luz del análisis de la coyuntura actual, lo cual se convierte en el elemento central de la educación, como Maria Montessori proponía en su pedagogía científica.

Nuestros intentos de comprensión necesariamente requieren:

- Una relativa libertad de acción, de palabra, de expresión, con el fin de intentar dilucidar, integralmente y sólo en ese contexto, las acciones y los eventos.

- Un ambiente físico-social dinámico, propuesto para los niños y niñas y examinado conforme observamos sus actuaciones, lo mismo que los valores sociales y culturales que hemos plasmado en el ambiente (concepto de ambiente preparado de Montessori).

- La autocrítica, el análisis y la reflexión conjunta. Como fundamentos: nuestra subjetividad, nuestras concepciones evolutivas de la infancia y de la sociedad, visibilizadas en discusiones grupales.

¿Qué mundo ponemos a su disposición? ¿En qué momentos reflexionamos sobre nuestras metas, nuestros sentimientos, nuestro quehacer pedagógico, nuestra visión del futuro? ¿Cómo abrimos las puertas al propio aprendizaje y desarrollo? ¿Nos concebimos como aprendices?

Atentas y atentos a lo que aprende y cómo aprende cada niño o niña, cómo actúa frente a determinadas situaciones, nuestro papel es sumamente activo: observarles tanto a ellos y ellas como nuestras propias actuaciones y teorías, para dilucidar cómo llevarles más adelante. Regresa a la actividad cotidiana, manifestándose en cambios gozosos en el ambiente o en 
nuestro actuar, en forma cíclica e integral. Tres pasos inextricablemente ligados: observación, reflexión interpretativa, acciones concordantes, en una lectura hermenéutica de las vivencias, haciendo relecturas constantes ${ }^{13}$.

Desde la investigación-acción, las propuestas de la cosmovisión transaccional son interesantes: la realidad es multifacética y el ángulo con que la miremos nos dará distintas perspectivas. Esta cosmovisión nos invita a examinar las formas en que teorías implícitas nos llevan a explicarnos diversas actividades y actuaciones con conceptos poco cuestionados. Se posibilita cuando varias cabezas y corazones 'piensan' en conjunto, con apego a situaciones específicas, con apertura y espacio para aproximaciones siempre emergentes a la construcción de la 'realidad'.

Esta decodificación abarca los actos cotidianos, en cada dimensión significativo-existencial: el vestíbulo, el recibimiento de niños, niñas y familiares, la forma de organizar la merienda, los materiales y su disposición en el entorno, la relación con los exteriores, con la agricultura... Y, por supuesto, no partimos desde cero ni desde una posición ecléctica, sino desde los legados de pensadores y pensadoras que nos preceden, cuyas teorías y prácticas también decodificamos en cuanto a su coherencia con los valores asumidos a la luz de la coyuntura sociohistórica. La decodificación de lo cotidiano favorece la integración entre la reflexión teórica y la puesta en práctica en la actualidad (Chavarría, et al., 2000a, 2000b).

La concientización sobre mensajes y valores implícitos en el medio nos lleva a examinar cómo la organización del espacio y la variedad y calidad de los materiales nos dice mucho sobre lo que se espera que los pequeños y las pequeñas hagan durante su permanencia en el centro. Por ejemplo, al encontrar en el ambiente la estructura y el orden de las ciencias y de los diversos quehaceres humanos, ofrecemos una organización concreta para que contacten estos aspectos, creando su propio orden, organizando sus conceptos. A través de este orden, también aprenden a confiar en la organización de su ambiente y en su propio poder de actuar en formas positivas.

\section{El lenguaje desde las mujeres vs. la secuestración de la experiencia}

La calidad de vida dirimida desde el lenguaje del amor, más que del interés político-económico, ha sido sistemáticamente estatizada, esterilizada, tecnificada. Desvirtuadas las maneras propias de asumir nuestras formas más sabias de interpretar y actuar sobre los mundos de nuestros hijos e hijas; desfiguradas como objetivos, poblaciones meta y normativas de una amplia gama de instituciones estatales, se nos desempodera, como madres, padres y educadoras, para instarnos a entregar nuestra autoridad a profesionales e instituciones cuyos paradigmas de planificación y administración modernizantes se rigen desde una lógica de la administración pública y no desde nuestra humanidad.

La culpa y la responsabilidad recaen sobre las mujeres-madres, para lo cual se presta la palabra alienada ("el problema de las madres que trabajan", "buscar quién me cuide a los hijos, "mi compañero es muy considerado, me ayuda"). Por supuesto, no elaboramos ponencias sobre los padres que trabajan y quién les cuida a sus hijos e hijas. No hacemos leyes para "proteger la integridad familiar" cuando "los padres trabajan". No hemos descubierto que el problema es el de familias donde los progenitores trabajan remuneradamente, en un sistema de tiempos alienados que coartan sus posibilidades de ejercer su quehacer como tales. Y por ende, en primera plana, de la sociedad como tal ${ }^{14}$.

A la vez, muchas mujeres trabajamos en este campo, pero las metas y las 
formas de organizar el quehacer cotidiano provienen desde el lenguaje de la administración pública, la concepción que ha caracterizado a nuestro capitalismo avanzado, dejando de lado las metas y las formas del amor. Nuestra palabra, desposeída de poder, no debe preguntar, compartir, reflexionar, sorprender, pero sí dedicar sus esfuerzos a escribir planes de trabajo desde la administración institucional.

Como en muchos campos, nuestra visión desde la mujer, como mujeres, se ha encontrado confundida, silenciada, sustituida por voces que se dirimen desde las palabras técnicas, desde las metas de 'desarrollo económico', desde la perspectiva de una 'ciencia' que no cuestiona ni la validez de sus supuestos y de sus conjeturados métodos objetivos, ni las posibilidades de una sola adulta de hacerse cargo del desarrollo integral de veinte pequeñines, amén de las angustias de las madres y de la distancia de muchos padres. No en vano es el movimiento feminista el que ha encausado las mayores contiendas hacia un cambio en los estilos de vida.

¿Hacia dónde encausamos nuestro destino como individuos y como sociedad? A partir de una atomización social sofisticada, parecen vanos nuestros intentos de educar a un ser con la integración necesaria para propiciar la paz. A partir de una familia fragmentada (madre-mujer-a-cargo-sin-voz y dispersada en mil pedazos ¿y el padre...?); a partir de nuestra alienación disociativa como educadoras; a partir de una multiplicidad de instituciones que duplican objetivos y hacen triplicar esfuerzos, en vano esperamos educar un ser social con la integración necesaria para propiciar la paz (Chavarría, 1993). Estamos nadando contra corriente.

Los esfuerzos orientados a plasmar estos principios en nuestro acontecer cotidiano requieren fortaleza interior y prácticas de cuidado personal por parte de las docentes y los docentes. No somos supermujeres, sino personas que estamos también tratando de actualizarnos. Necesitamos explorar las condiciones que nos den momentos de gozo, tranquilidad, empatía con otras personas desde nuestra propia vivencia. Usualmente, las condiciones de trabajo túa-tú que propicia la visión de marco abierto aquí propiciada presenta muchas aperturas y resulta más gratificante que la dirección y control grupal, en parte porque el grupo mismo asume funciones de colaboración y autorregulación con un gran compromiso, aún entre los más pequeños y las más pequeñas. Aún así, la enorme multiplicidad de funciones que asumimos genera la imperiosa necesidad de defender nuestras condiciones de trabajo para crear un mundo de vida más acorde con la visión que aboga por trascender la alienación circundante.

Buscar el respaldo de los seres que nos rodean, de talleres al respecto, de la naturaleza, la meditación y otras actividades relajantes y enriquecedoras, podrán constituir pasos necesarios para vivir estas prácticas con gozo e integración personales, pues al haber crecido en esta misma sociedad, muchas veces no hemos tenido acceso a vivencias de esta índole.

Es perentorio contar con un equipo que apoye nuestros intentos de integrar estos principios a la realidad, tarea difícil de asumir ante las condiciones usuales de sobrecarga, competencia y resistencia institucional que caracterizan nuestra labor docente. Afianzar nuestras propias vivencias de paz representa, en sí, un enorme reto en la coyuntura actual. El rescate de estas vivencias, junto con los pequeños y las pequeñas, puede proporcionarnos enormes fuentes de gozo, como hemos tratado de demostrar en nuestras prácticas (cf. Chavarría et al., 2000a, 2000b).

La formación de nuestros niños y niñas se gesta en el presente. Cuantos más presentes dejemos pasar en condiciones que lesionan su integridad, más generaciones de adultos violentos o apáticos estaremos contribuyendo a crear. Más democracias en la ignorancia, más políticos con las 
miras puestas en el bienestar de unos cuantos... Este es el argumento más sobresaliente para hablar de educación para la paz y el desarrollo sostenible. ¿No sería deseable que a pesar de las divisiones, nos uniera la necesidad de contar con un presente y un futuro viables?

\section{Notas}

1. Este artículo fue escrito como parte del proyecto de investigación "Preescolar con principios de paz y desarrollo sostenible", auspiciado por el Instituto de Investigaciones Psicológicas, el Centro Infantil Laboratorio (CIL) de la Universidad de Costa Rica y la Embajada Real de los Países Bajos. Agradezco los comentarios de las colegas Cynthia Orozco Castro, Mabel Ovares Gutiérrez, Lorena Sáenz Segreda y Marco A. Quirós Méndez. Al CIL, mi sentido agradecimiento por dar vida, en el análisis permanente y cotidiano, a esta visión, sin el cual estos principios esbozados quedarían como un ideario en el papel.

2. Así denominada por Giddens, 1995.

3. Consúltese Giddens (1995) para un lúcido análisis de los condicionantes de despojo y posibilidades de reapropiación mediante políticas emancipatorias y políticas de vida contestatarias.

4. Para desarrollar los indicadores de calidad, nos apoyamos en Bruner (1966), Freire (1970), Laing (1960, 1972, 1974), Montessori (1967), Rogoff (1990, 1994, 1997), Stern (1985), Vygotsky (1962, 1987), Wallon (1942/1974). También en Kamii y DeVries (1972), quienes intentan brindar una interpretación más dinámica, menos empirista, de Piaget. Asimismo, son tomadas muy en cuenta las sugerencias de Hymes (1974) quien, con base en un sensitivo enfoque simultáneamente centrado en el niño, en la sociedad y en la materia, provee un desglose razonado de indicadores básicos de calidad en centros de atención infantil.

5. Resaltan los nombres de Freire, 1986; Habermas, 1985/1989; Laing, 1972, 1974, 1976; Mounier, 1965, 1967; Vygotsky, 1962, 1987.

6. El concepto de influencia recíproca se considera débil en una concepción dialéctica o transaccional, donde la definición misma de los conceptos depende de las estructuras socioeconómicas que se filtran en nuestras definiciones y enfoques.

7. Esto tiene, ciertamente, implicaciones políticas, al tratar de propiciar la permanencia del personal y de organizar las prácticas de estudiantes a lo largo del año, como se comentará más adelante.

8. Estas son normas recomendadas para los Estados Unidos, lo cual sería irrealizable en la mayoría de los países del Tercer Mundo. Las cifras oficiales del Ministerio de Educación costarricense indican 20 niños por adulto en el nivel materno-infantil, 30 en el ciclo de transición, en área urbana, lo cual, a nuestro parecer, indica alta escolarización, especialmente preocupante para el nivel materno-infantil (cf. Chavarría y Pérez, 1992).

9. Algunas se sugieren en Chavarría y Pérez (1992) y en Chavarría (1993).

10. Como hemos insistido en Tendencias políticas de la educacón preescolar: el dilema de la madre trabajadora (Chavarría, 1993), se requiere de una gran creatividad estatal para integrar a personas voluntarias a las aulas de educación inicial, con el fin de poder proporcionar estructuras de marco abierto a nuestra niñez, pues una docente a cargo de 20 o 30 niños y niñas no puede fácilmente proporcionar las alternativas necesarias.

11. Recomendación específica de la Licda. Marcela Hio, del CIL, para favorecer que ciertas áreas fuesen más utilizadas por las chicas y viceversa.

12. Montessori se refiere a los períodos sensibles: "un intenso interés de repetir ciertos actos extensamente, sin ninguna razón evidente, hasta que -debido a esa repetición-, una función fresca aparece de repente con fuerza explosiva" (Montessori, 1964:86).

13. Consúltese al respecto nuestro enfoque al ecoanálisis como instrumento de decodificación de lo cotidiano (Chavarría y Orozco, en proceso-a; Chavarría et al., 2000a).

14. Una serie de alternativas de organización social al respecto se sugieren en Chavarría, 1993; consúltense también las reflexiones pioneras de Betty Freiedan (1965). 


\section{Referencias bibliográficas}

Apple, M.W. Educación y poder. Barcelona: Paidós. 1988.

Bramadat, D. El principio femenino como valor del nuevo milenio. San José, Costa Rica: Taller. 1995.

Bourdieu, P. y Passerson, J.C. La reproducción: elementos para una teoría del sistema de enseñanza. México, D.F.: Fontamara. 1996.

Brooke Medicine. For the love of God (1990); cit. por Spenard, C. Un tesoro de sabiduría femenina. 1997.

Bruner, J. Towards a theory of instruction. New York: W.W. Norton. 1966.

Carnoy, M. Educación como imperialismo cultural. México, D. F.: Siglo XXI. 1976.

Cordero, T. Experiencias pedagógicas de las madres-maestras: comprendiendo los significados de las actividades del Jardín. Universidad de Costa Rica, Doctorado Latinoamericano de Educación; anteproyecto de tesis presentado en julio 2002 .

Coelho, P. Palabras esenciales. Buenos Aires, Argentina: Vergara \& Riba. 1998.

Chavarría, M.C. "La estimulación temprana: Apuntes sobre sus fundamentos teóricos, bases empíricas y raíces socio-históricas." Revista de Ciencias Sociales (Costa Rica), 23: 41-56. 1982.

Chavarría, M.C. Guía de observación y evaluación en centros infantiles: Algunas orientaciones para padres $\mathrm{y}$ maestros. Avances de Investigación,
Instituto de Investigaciones Psicológicas. 7 (62). 1991a.

Chavarría, M.C. La estructura de la educación preescolar en Costa Rica. Avances de investigación: Instituto de Investigaciones Psicológicas. 7 (63). 1991b.

Chavarría, M.C. Tendencias sociopolíticas de la educación preescolar: El dilema de la madre trabajadora. San José: Editorial de la Universidad de Costa Rica. 1993.

Chavarría, M.C. y Orozco, C. "Arco iris de posibilidades": Un instrumento para la exploración de posibilidades y transformaciones en el ambiente-situación. San José, C.R.: Universidad de Costa Rica: IIP. (en proceso-a).

Chavarría, M.C. y Orozco, C. "Calidad del centro infantil (cci)": Criterios para madres, padres y docentes. San José, C.R.: Universidad de Costa Rica: IIP. (en proceso-b).

Chavarría, M.C. y Pérez, M. El reto de la educación preescolar en una sociedad cambiante. San José, C.R.: Ed. Universidad de Costa Rica. 1992.

Chavarría, M.C.; Orozco, C.; Chacón, Y. y Ovares, M. "Aciertos y vicisitudes en la búsqueda de valores hacia la paz y el desarrollo sostenible: la decodificación de lo cotidiano como herramienta teórico-práctica". Revista Costarricense de Psicología, 31. 2000a.

Chavarría, M. C.; Orozco, C.; Chacón, Y.; Ovares, M., y Obando, M. del M. "La formación del preescolar como cosmovisión: en busca de valores hacia la paz y el desarrollo sotenible". Educación: Revista de la Universidad de Costa Rica, 24 (No. 2), 115-132. 2000 b. 
De Alba, A. "El currículum universitario ante los retos del siglo XXI: La paradoja entre postmodernismo, ausencia de utopía y determinación curricular." En: De Alba, A. (coord.) El currículum universitario de cara al nuevo milenio. México: Centro de estudios sobre la universidad. 1993.

Dengo, O. Escritos y discursos. Costa Rica: Ministerio de Educación Pública. 1915/1961.

Doke, L. A. "The organization of day care environments: Formal versus informal activities." En: D. L. Peters (comp.), Day care: Problems, processes, prospects. New York: Human Sciences Press, pp. 216-222. 1975.

Berrón, L. (Editora). Las mujeres y el poder. San José: Editorial Mujeres. 1997.

Fernández Christlieb, P. "Consideraciones teórico-metodológicas sobre la psicología política." En: Montero, M. (comp.), Psicología política latinoamericana. Caracas: PANAPA. 1987.

Frankl, V. Psicoanálisis y existencialismo. México, D.F.: Fondo de Cultura Económica. 1946/1963.

Freire, P. Pedagogía del oprimido. México, D.F.: Siglo XXI. 1986.

Friedan, B. The feminine mystique. Hamondsworth: Pelican, 1965.

Fromm, E. Man for himself. Grenwich, Conn: Fawcett Publications. 1965.

Fromm, E. The forgotten language. Grenwich, Conn: Fawcett Publications. 1969.
Giddens, A. Modernidad e identidad del yo: El yo y la sociedad en la época contemporánea. (Traducción de J.L. Gil Aristu). Barcelona: Península. 1995.

Giroux, H. Los profesores como intelectuales. México, D.F.: Paidós. 1990.

Giroux, H. Schooling and the struggle for public life. Minneapolis, Minn: University of Minnesota Press. 1988.

González, Luisa. A ras del suelo. San José, Costa Rica: Editorial Costa Rica. 1990.

Gutiérrez, F. Pedagogía de la comunicación en la educación popular. Madrid: Editorial Popular. 1993.

Habermas, J. Legitimation crisis. Londres: Heinemann. 1976.

Habermas, J. Teoría de la acción comunicativa. Barcelona: Taurus. 1987.

Habermas, J. El discurso filosófico de la modernidad. Barcelona: Taurus. 1989.

Hernández Cruz, O. "Rituales de iniciación escolares. El caso de una escuela caribeña costarricense". Educación: Revista de la Universidad de Costa Rica, 24 (No. 2), 62-73. 2000.

Hymes, J. L. Teaching the child Ander six. Columbus, Ohio: Charles E. Merrill. 1974.

Kamii, C. y DeVries, R. "Piaget for early education”. En M.C. Day y R.A. Parker (eds): The pre-school in action: Exploring early childhood programs. Boston: Allyn \& Bacon. 1972. 
Laing, R. The divided self. Londres: Tavistock. 1960.

Laing R. The politics of experience. New York: Ballantine Books. 1972.

Laing R. El yo y los otros. México, D.F.: Fondo de Cultura Económica. 1974.

Lave, J., y Wenger, E. Situated learning: Legitimate peripheral participation. Cambridge, England: Cambridge University Press. 1991.

Leontiev, A. El desarrollo del psiquismo. Madrid: Akal. 1983.

Meadows, F. "Desarrollo motor y control de movimientos a través de ejercicios de la vida práctica". Material de capacitación. San José, Costa Rica. 1996.

Merani, A. Psicología y alienación. Mexico, D.F.: Grijalbo. 1973.

Myers, R. "Atención y desarrollo de la primera infancia en Latinoamérica y el Caribe: una revisión de los diez últimos años y una mirada hacia el futuro". En: Revista Iberoamericana de Educación, España: OEI, \#22. Enero-abril, pp. 17-60. 2000.

Metzner, R. En Roszak, T. (ed). Ecopychology. San Francisco: Sierra Club Books. 1995.

Monge Alfaro, C. y Rivas Ríos, F. La educación: Fragua de nuestra democracia. San José, Costa Rica: Editorial Universidad de Costa Rica. 1978.

Montessori, Maria. The absorbent mind. New York: Dell. 1967.

Montessari, Mario, Jr. La educación para el desarrollo humano. México, D.F.: Editorial Diana. 1986.
Mounier, E. El personalismo. Buenos Aires: Editorial Universitaria. 1965.

Mounier, E. Manifiesto al servicio del personalismo. España: Ediciones Taurus. 1967.

Pérez Gómez, A. La cultura escolar en la sociedad neoliberal. Madrid: Editorial Morata. 1998.

Rogoff, B. Apprenticeship in thinking: cognitive development in social context. New York: Oxford University Press. 1990.

Rogoff, B. "Developing understanding of the idea of communities of learners". En: Mind, Culture, and Activity, vol. 1, No. 4. 1994.

Rogoff, B. "Evaluating development in the process of participation: Theory, methods, and practice building on each other". En: E. Amsel \& A. Renninger (eds), Change and development. Hillsdale, N.J.: Erlbaum. 1997.

Rojas, M. Educación científica y matemática para el niño preescolar: Perspectiva constructivista. San José, Costa Rica: Editorial EUNED. 1998.

Roszak, T. (ed). Ecopsychology. San Francisco: Sierra Club Books. 1995.

Salas Madriz, F.E. "Ética y administración educativa: Retos y desafíos de la coyuntura actual." Educación: Revista de la Universidad de Costa Rica, 24 (No. 2). 2000.

Steinfels, M.O. Who's minding the children? History and politics of day care in America. New York: Simon y Schuster. 1973.

Stern, D.N. The interpersonal world of the infant: A view from psychoanalysis 
and developmental psychology. Nueva York: Basic Books. 1985.

Tamaro, S. Donde el corazón te lleve. Barcelona: Editorial Seix Barral. 1998.

Tamaro, S. Querida Mathilda: No veo el momento en que el hombre eche a andar. Barcelona: Editorial Seix Barral. 1998.

Van de Kieft, K. Innersource. (1988); en Spenard, C. Un tesoro de sabiduría femenina. 1997.

Vygotsky, L. Thought and language. Cambridge, Mass.: MIT Press. 1962.

Vygotsky, L. Historia del desarrollo de las funciones psíquicas superiores. La
Habana: Editorial Científico Técnica. 1987.

Wallon, H. (1941). L'evolution psycologique de l'enfant. Paris: Colin. Traducción al español de Mario Miranda. La evolución psicológica del niño. México, D.F.: Grijalbo, 1974).

Werner, C. y Altman, I. A dialectical transactional framework of social relations: Children in secondary territories. En: Görlitz, et al. (comps.), Children, cities and psychological theories. Berlín: Walter de Gruyter. 1998.

Wertsch, J.V. Vygotsky y la formación social de la mente. Barcelona: Paidós. 1988.

María Celina Chavarría González Investigadora del Instituto de Investigaciones Psicológicas de la Universidad de Costa Rica. 